\title{
Localization of neonatal Fc receptor for $\lg G$ in aggregated lymphoid nodules area in abomasum of Bactrian camels (Camelus bactrianus) of different ages
}

\author{
Wang-Dong Zhang, Wen-Hui Wang*, Shu-Xian Li, Shuai Jia, Xue-Feng Zhang and Ting-Ting Cao
}

\begin{abstract}
Background: The neonatal Fc receptor ( $F C R n$ ) plays a crucial role in transporting IgG and associated antigens across polarized epithelial barriers in mucosal immunity. However, it was not clear that FcRn expression in aggregated lymphoid nodules area (ALNA) in abomasum, a unique and important mucosal immune structure discovered only in Bactrian camels. In the present study, 27 Alashan Bactrian camels were divided into the following five age groups: fetus (10-13 months of gestation), young (1-2 years), pubertal (3-5 years), middle-aged (6-16 years) and old (17-20 years). The FcRn expressions were observed and analyzed in detail with histology, immunohistochemistry, micro-image analysis and statistical methods.

Results: The results showed that the FcRn was expressed in mucosal epithelial cells of ALNA from the fetus to the old group, although the expression level rapidly declined in old group; moreover, after the ALNA maturated, the FcRn expression level in the non-follicle-associated epithelium (non-FAE) was significantly higher than that in FAE $(P<0.05)$. In addition, the FcRn was also expressed in the vessel endothelium, smooth muscle tissue, and macrophages and dendritic cells (DCs) of secondary lymphoid follicles (sLFs).

Conclusions: It was demonstrated that FcRn was mainly expressed in non-FAE, the effector sites, although which was expressed in FAE, the inductive sites for mucosal immunity. And it was also expressed in DCs and macrophages in SLFs of all ages of Bactrian camels. The results provided a powerful evidence that IgG (including $\mathrm{HCAb}$ ) could participate in mucosal immune response and tolerance in ALNA of Bactrian camels through FcRn transmembrane transport.
\end{abstract}

Keywords: Neonatal Fc receptor (FcRn), Expression, Aggregated lymphoid nodules area (ALNA), Bactrian camels, Epithelium, Mucosal immunity

\section{Background}

In mucosal immunity, polymeric immunoglobulin receptor (pIgR) is an important receptor, which helps to maintain mucosal barrier integrity and gastroenteric homeostasis by transporting secretory immunoglobulin A (SIgA) antibodies across intestinal epithelial cells (IECs) into gut secretions [1-5]. As well, the neonatal Fc receptor $(\mathrm{FcRn})$ also plays a crucial role in transporting IgG and associated antigens across polarized barriers [6-11]. It is

\footnotetext{
* Correspondence: wwh777@126.com

College of Veterinary Medicine, Gansu Agricultural University, Lanzhou, Gansu 730070, China
}

another important receptor regulating mucosal immune onse. mpatibility complex $(\mathrm{MHC})$ class I-related receptor due a membrane-bound heavy chain that consists of three soluble domains ( $\alpha 1, \alpha 2$ and $\alpha 3)$, a single transmembrane helix, and a small cytoplasmic domain [14]. Although FcRn was originally named according to its expression 
pattern in rodent IECs where it was first identified, FcRn is now known to be expressed throughout life in many different cell types across the body [15-25]. However, the FcRn expression characteristics markedly differ with different species. For instance, in human intestinal epithelial cells, FcRn is expressed in both fetus and adult $[15,26]$. By contrast, it is only highly in newborns and the level rapidly declines after weaning in mouse [27, 28]. In addition, the range of animals in which FcRn orthologs have also been identified includes rabbit [29], pig [30], sheep [31], bovine [32], Egyptian water buffalo [33], and dromedary [34].

Bactrian camel is an important livestock of economic characteristics in northwest of China and has some special immunological features. First, compared with the structure of conventional IgG, the Camelidae IgG2 and IgG3 are special heavy chain antibodies (HCAbs) [35], which are naturally devoid of light chain and their antigen binding site only consists of a single domain [36]. Second, compared with other livestock [37], Chinese Alashan Bactrian camels have a unique aggregated lymphoid nodule area (ALNA) in the abomasum [38]. This species-specific anatomical structure could be divided into the reticular mucosal folds region (RMFR) and longitudinal mucosal folds region (LMFR) [38-40]. They belonged to the organized mucosaassociated lymphoid tissue (MALT). However, the FcRn expression in this region has not been reported at present. Based on our previous researches on the morphology and histology of ALNA [38-40], the characteristics of $\mathrm{FcRn}_{\mathrm{C}}$ expression with age in this area were studied in this paper. We hope that it will provide the necessary immunomorphology support for further studying whether FcRn could participate in mucosal immunity in this area or not.

\section{Methods}

\section{Experimental animals}

Twenty-seven Alashan Bactrian camels of different ages (half male and half female, except fetus group) were divided into five age groups: fetus (10-13 months' gestation, $n=3$, two males and one female), young ( $1-2$ years, $n=6)$, pubertal $(3-5$ years, $n=6)$, middle-aged (6-16 years, $n=6)$ and old (17-20 years, $n=6$ ). Fetus tissues were collected from animal carcasses submitted to the necropsy service in College of Veterinary Medicine, Gansu Agricultural University. Other animals were from the slaughterhouse (Xining, Qinghai province of China) and were not starved before slaughter, which were anaesthetised intravenously with sodium pentobarbital $(20 \mathrm{mg} / \mathrm{kg})$ and then exsanguinated to death.

\section{Microsection}

The whole abomasum from the isthmus to the pyloric ostium was incised along the greater curvature. The gastric contents were cleaned with saline. Samples from RMFR and LMFR of ANLNA were rapidly taken after death and fixed in $10 \%$ neutral formalin. The paraffin sections were made and stained with haematoxylin and eosin (H\&E) by a routine method [41] as well as SABC-immunohistochemistry (IHC) by the method as follows: the samples were sectioned $(4 \mu \mathrm{m})$ and placed on the polylysine-coated slides (molecular weight: 150, 000-300,000; working concentration: $0.10 \%(w / v)$ solution in water, Sigma, USA). After deparaffination, we used $1.0 \mathrm{mg} / \mathrm{ml}$ trypsin 1: 250 (250.N.F.U/mg, Sigma, USA) for enzyme-induced epitope retrieval, which was followed by endogenous peroxidase blocking $\left(3 \% \mathrm{H}_{2} \mathrm{O}_{2}\right)$. For blocking, $5 \%$ bovine serum albumin (BSA, from easy-to-use immunohistochemical kit, Lot No.07H3OCJ, Boster, Wuhan, Hubei, China) was used. All samples with the primary antibody were incubated at $4{ }^{\circ} \mathrm{C}$ overnight. After being rinsed with PBS 2 min $\times 3$ times; HRP conjugated goat anti-rabbit IgG (from easy-to-use immunohistochemical kit, Lot No.07H3OCJ, Boster, Wuhan, Hubei, China) as secondary antibody was applied for $1 \mathrm{~h}$ in humidified box at $37^{\circ} \mathrm{C}$. After being rinsed with PBS $5 \mathrm{~min} \times 4$ times. The SABC was applied for $30 \mathrm{~min}$ in humidified box at $37{ }^{\circ} \mathrm{C}$. After being rinsed with PBS 5 min $\times 4$ times. For detection, DAB Kit (ZSGB-BIO, Beijing, China) was used at room temperature. Slides were counterstained with Hematoxylin (Solarbio, Beijing, China) and mounted with Neutral Balsam (Solarbio, Beijing, China). Sections were examined with an Olympus microscope (Olympus, Hamburg, Germany) [42].

\section{Primary antibodies selection and analysis}

Rabbit polyclonal antibodies against human FcRn, diluted with the buffer at $3.33 \mu \mathrm{g} / \mathrm{ml}$ before use, was supported by BIOSS (Lot No. 140226, BIOSS, Beijing, China).

Some studies reported that the $\mathrm{drFcRn} / \mathrm{Fc}$ contact residues were highly conserved, and the structures of FcRn in different species were similar [14, 34, 43]. Hence, the epitopes of FcRn are similar among different species. Moreover, in immune responses, MHCII presents antigens to $\mathrm{CD} 4^{+} \mathrm{T}$ cells, and the antigen peptide should be composed of more than 12 amino acid residues. The molecular weight of human FcRn is about $50 \mathrm{kDa}$. Moreover, the similarity of FcRn between dromedary and human was $78.6 \%$ by analyzing the genes of phylogenetic relatedness of the extracellular domains $(\alpha 1-\alpha 2-\alpha 3)$ [34]. Therefore, this primary antibody well met the sequent experiment request. 


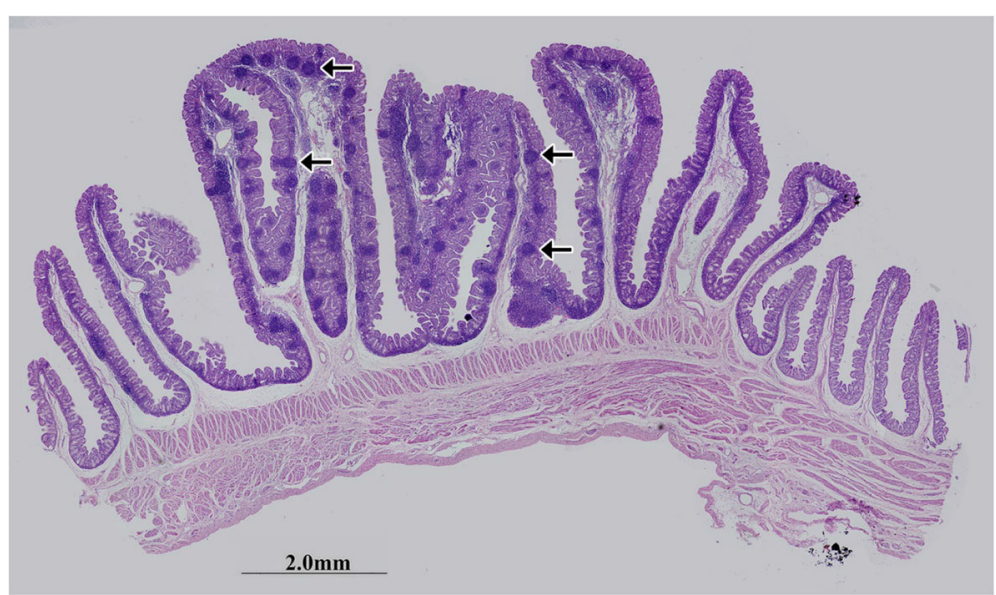

Fig. 1 Histological characteristics of the RMFR in fetus group. A plenty of primary lymphatic follicles (pLFs) (arrow) were seen in this area and they were mainly distributed in the lamina propria (LP). Original magnification: 40X

\section{Second antibodies}

SABC goat anti-rabbit IgG polyclonal antibodies immunohistochemical kit (Lot No.07H3OCJ, Boster, Wuhan, Hubei, China). The kit contained 1.5\% BSA:12 ml. Second antibodies: Biotin goat anti rabbit IgG: $12 \mathrm{ml}$. SABC: $12 \mathrm{ml}$. It is an easy-to-use kit, which can be used directly and is unnecessary to be diluted with the buffer.

\section{Light microscopy}

In each group, the expression sites and characteristics of FcRn were observed in detail under microscope and photomicrographed using Olympus DP-71 microscopy system.

\section{Statistical analysis}

Five sections were randomly selected for each sample. Ten microscopic fields were randomly selected, observed and photomicrographed for FAE, non-FAE, vascular, smooth muscle and lymphoid follicle in each section. The mean optical density (MOD) of each site was calculated (Image-Pro Plus 6.0), respectively. The main steps contain: 1. the background correction of the IHC photos (this can make the light intensity in the central and around the IHC photos become consistent); 2 . the correction of the optical density of the IHC photos (this can change the image intensity to the optical density); 3 . the parameter setting (select the integrated optical density (IOD) as the measurement value of the ICH image); 4. selection the measurement region through the software tools; 5 . color settings; 6 . measurement of the IOD and the area of the selected region; 7. the calculation of the MOD through IOD/selected areas. The MOD differences among groups were analyzed by one-way ANOVA followed by Duncan's new multiple range test using IBM SPSS v. 23.0 (SPSS Inc., Chicago, USA). The significant difference was considered at $P<0.05$.

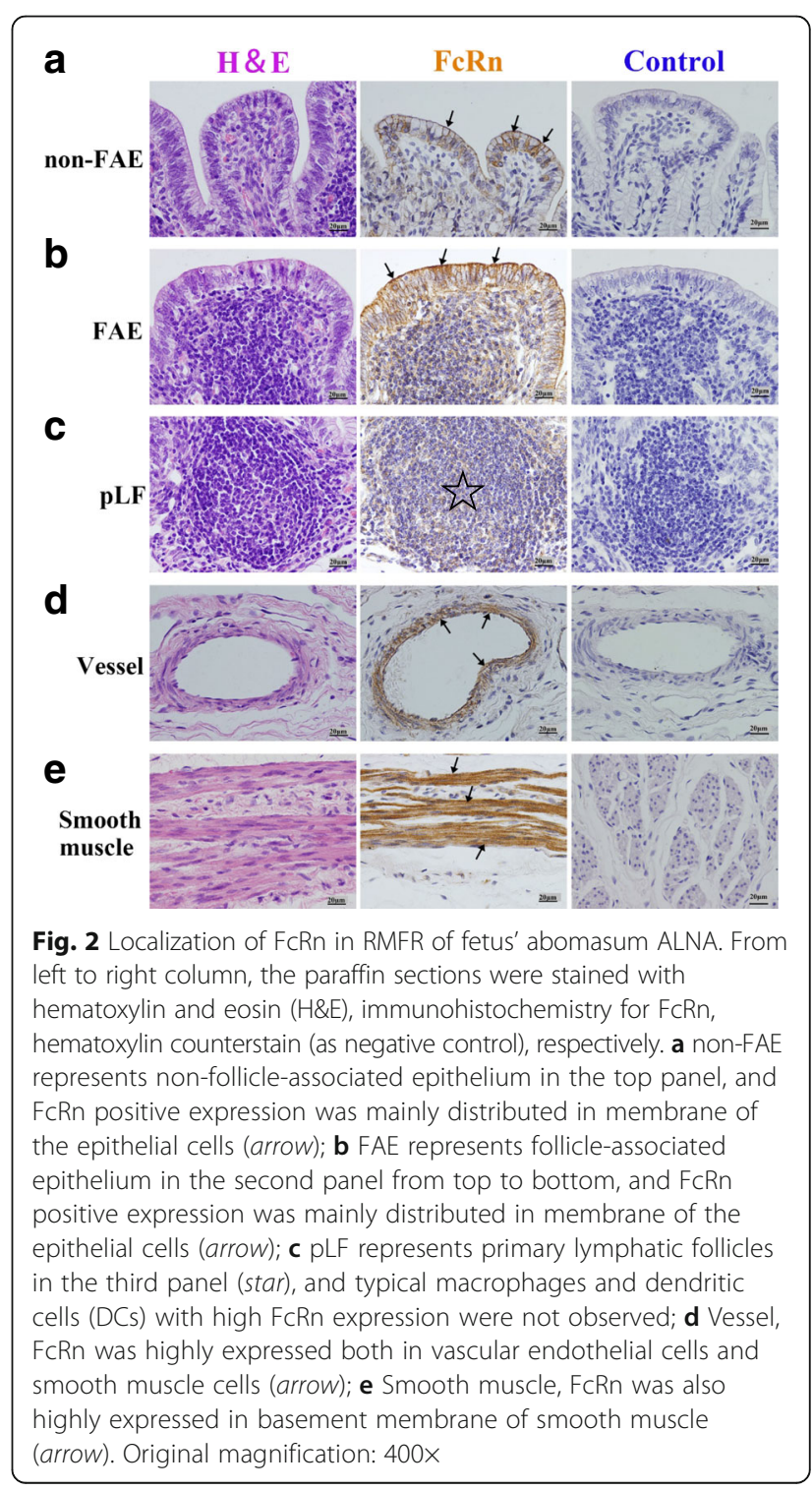




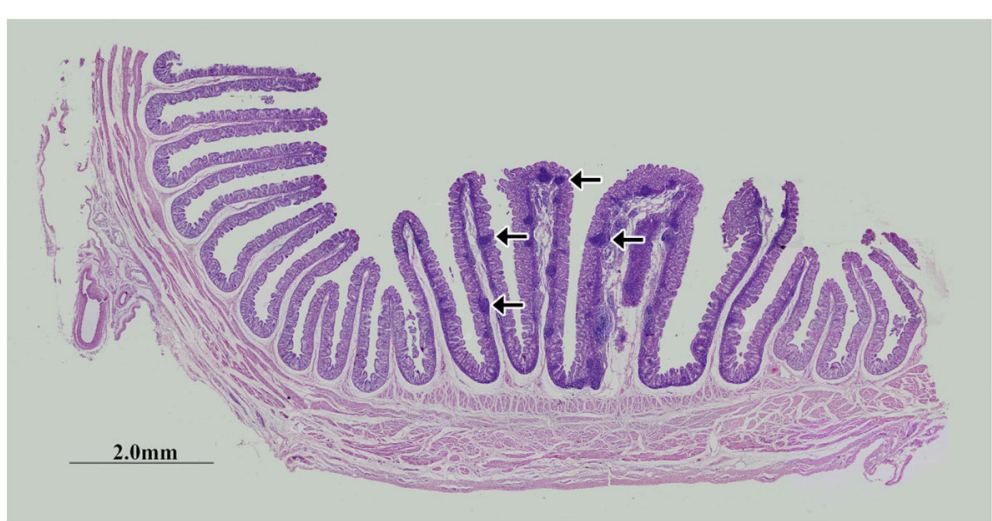

Fig. 3 Histological characteristics of the LMFR in fetus group. A certain amount of primary lymphatic follicles (pLFs) (arrow) were seen in this area. The distribution characteristics of pLFs were similar to those in RMFR, i.e., they were mainly distributed in the lamina propria (LP). Original magnification: $40 x$

\section{Results}

\section{Localization of FcRn in abomasum ALNA in Bactrian camels of different ages \\ Fetus group}

(1') In RMFR, a plenty of primary lymphatic follicles (pLFs) were primary densely-distributed in the lamina propria (LP) (Fig. 1). And FcRn was expressed in both non-follicle-associated epithelium (non-FAE) (Fig. 2a) and FAE (Fig. 2b), and mainly at the apical membrane. However, typical macrophages and dendritic cells (DCs) with high FcRn expression were not observed in the pLFs (Fig. 2c). In addition, the FcRn was also expressed in vessel endothelium (Fig. 2d) and smooth muscle tissue (Fig. 2e). (2') In LMFR, the histological characteristics were similar to those in RMFR. Lymphatic follicles were also pLFs. But the distribution density was lower than that in RMFR (Fig. 3). The localization of FcRn was similar to that in RMFR (Fig. 4a-e).

\section{Young group}

(1') In RMFR, a plenty of secondary lymphatic follicles (sLFs) were concentrated in the LP and submucosa (Fig. 5a). FcRn was highly expressed in typical macrophages and DCs in sLFs (Fig. 5b, c and d). Meanwhile, the FcRn was also expressed in non-FAE (Fig. 6a), FAE (Fig. 6b), vessel endothelium (Fig. 6c) and smooth muscle tissue (Fig. 6d). (2') In LMFR, the localization of FcRn was similar to that in RMFR (Figs. 7 and 8).

\section{Pubertal and middle-aged groups}

The localization of FcRn was in the two groups were both similar to those in young group.

\section{Old group}

The localization of FcRn was in RMFR and LMFR were similar. It was highly expressed in macrophages and

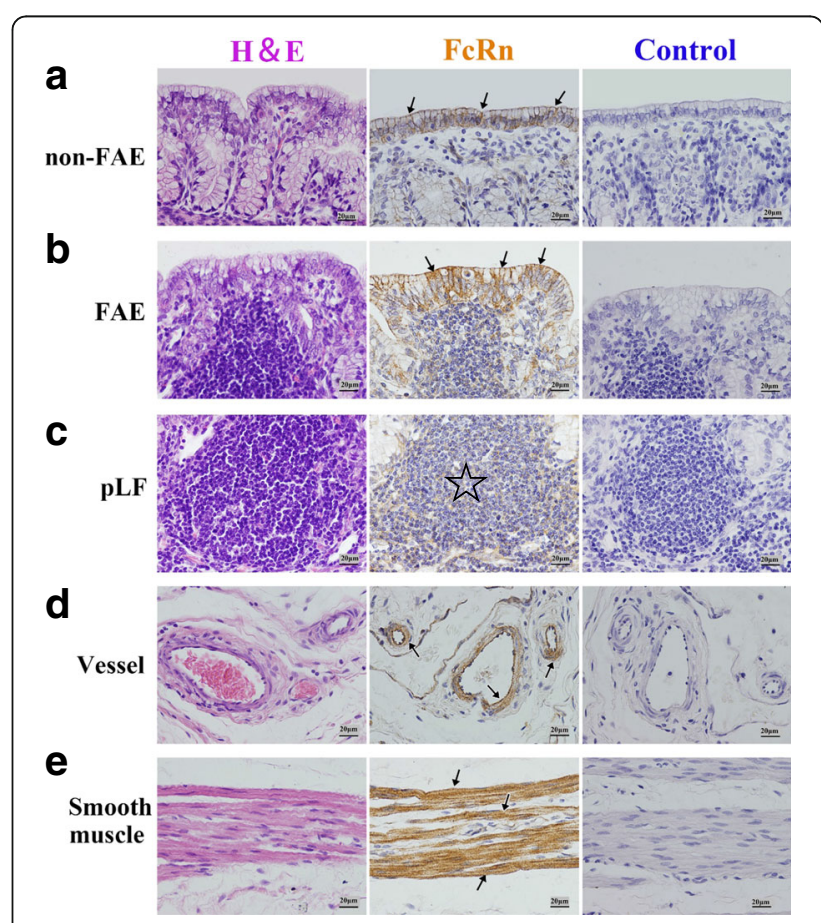

Fig. 4 Localization of FcRn in LMFR of fetus' abomasum ALNA. From left to right column, the paraffin sections were stained with hematoxylin and eosin (H\&E), immunohistochemistry for FCRn, hematoxylin counterstain (as negative control), respectively. a nonFAE represents non-follicle-associated epithelium in the top panel, and FcRn positive expression was mainly distributed in membrane of the epithelial cells (arrow); b FAE represents follicle-associated epithelium in the second panel from top to bottom, and FcRn positive expression was mainly distributed in membrane of the epithelial cells (arrow); c pLF represents primary lymphatic follicles in the third panel (star), and typical macrophages and dendritic cells (DCs) with high FcRn expression were not observed; $\mathbf{d}$ Vessel, FcRn was highly expressed both in vascular endothelial cells and smooth muscle cells (arrow); e Smooth muscle, FcRn was also highly expressed in basement membrane of smooth muscle (arrow). Original magnification: 400x 


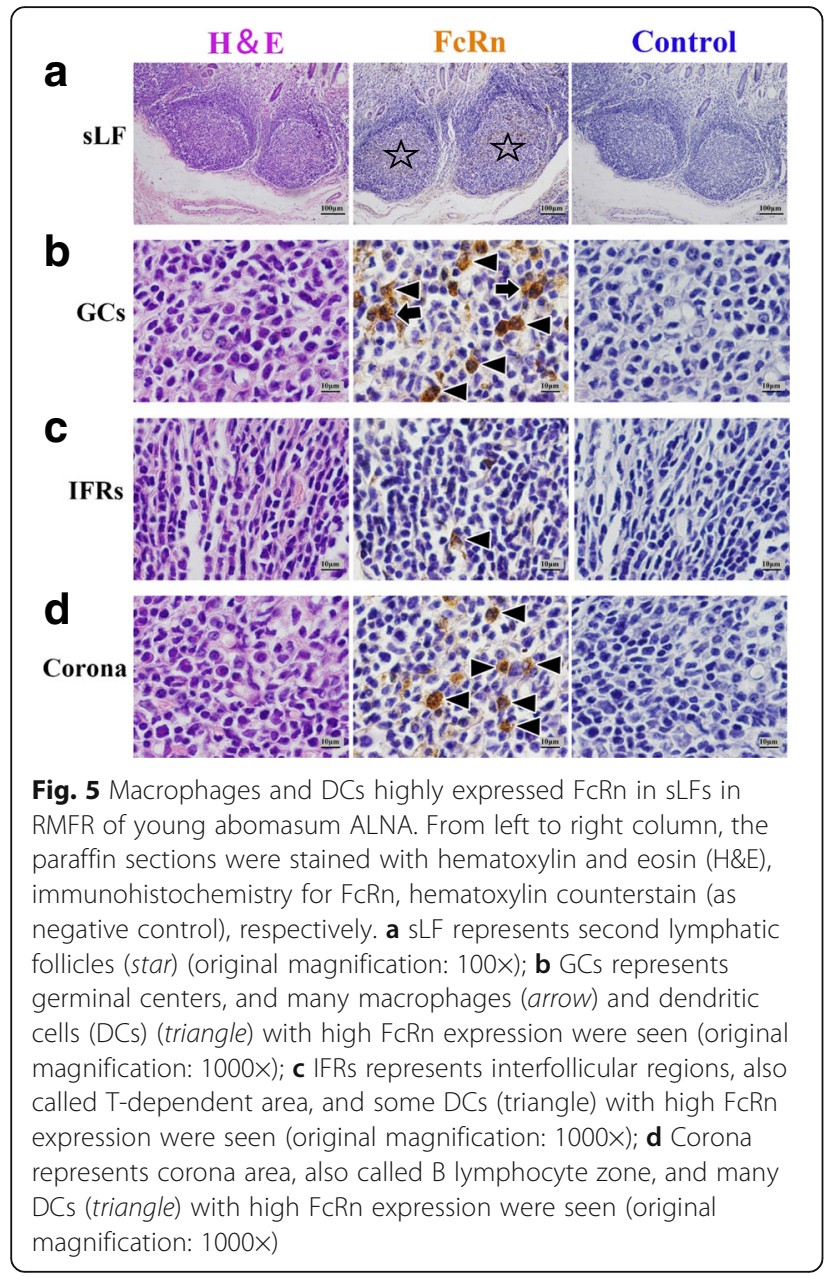

DCs in sLFs, however, the expression levels were very low in other tissues.

\section{FcRn expression levels in mucosal epithelium of abomasum ALNA with age \\ FcRn expression levels}

The MOD value detection results showed: (1') In RMFR, the FcRn expression level in non-FAE was significantly higher than that in FAE in young, pubertal and middleaged groups, respectively $(P<0.05)$ (Fig. 9b, c and d), but it had no significant difference in fetus and old groups $(P>0.05)$ (Fig. 9a and e); (2') In LMFR, the FcRn expression level in non-FAE was significantly higher than that in FAE in pubertal and middle-aged groups, respectively $(P<0.05)$ (Fig. $9 \mathrm{c}$ and $\mathrm{d})$, and it had no significant difference in other groups $(P>0.05)$ (Fig. 9a, $b$ and e).

\section{Changes in the FcRn expression with age}

(1') In RMFR, the FcRn expression level in FEA and non-FAE both gradually increased from fetus to pubertal

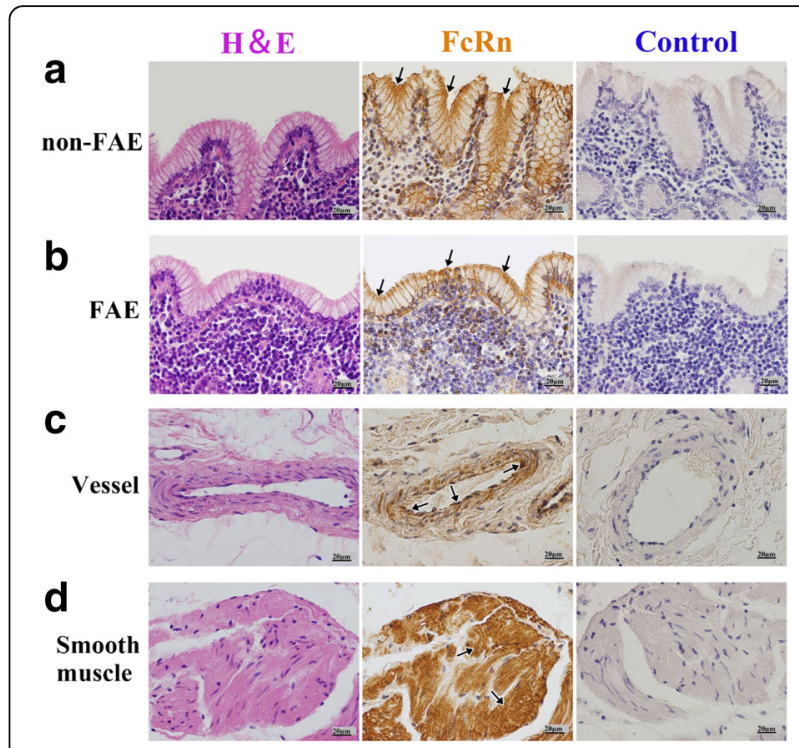

Fig. 6 Localization of FCRn in RMFR of young abomasum ALNA. From left to right column, the paraffin sections were stained with hematoxylin and eosin (H\&E), immunohistochemistry for FcRn,

hematoxylin counterstain (as negative control), respectively. a nonFAE represents non-follicle-associated epithelium in the top panel, and FCRn positive expression was mainly distributed in membrane of the epithelial cells (arrow); b FAE represents follicle-associated epithelium in the second panel from top to bottom and FcRn positive expression was mainly distributed in membrane of the epithelial cells (arrow), but the expression level was lower than that in non-FAE; c Vessel, FcRn was highly expressed both in vascular endothelial cells and smooth muscle cells (arrow); d Smooth muscle, FcRn was also highly expressed in basement membrane of smooth muscle (arrow). Original magnification: $400 x$

groups with increasing age, peaked in pubertal group, and subsequently gradually declined (Fig. 10a and b). (2') In LMFR, the FcRn expression level in FAE peaked in young and kept the high level to pubertal period, then subsequently significantly declined, but that in non-FAE gradually increased with increasing age, peaked in the middle-aged group (Fig. 10c and d). In addition, the FcRn expression level significantly decreased in the mucosa epithelium in old group $(P<0.05)$ (Fig. 10e).

\section{Discussion}

Organized MALT is a critical part of the mucosal immune system [44]. Wang et al. reported that there were developed ALNA in abomasum of Bactrian camel [38-40], which belonged to the organized MALT. Our result showed that FcRn was expressed in non-FAE of ALNA at different levels in all groups, which was compatible with the expression of FcRn in human enterocytes ( $F_{c} R n$ was expressed in adult human enterocyte) [15]. However, this was very different from the FcRn expression in the intestinal mucosal epithelium of rat [8], which was only 


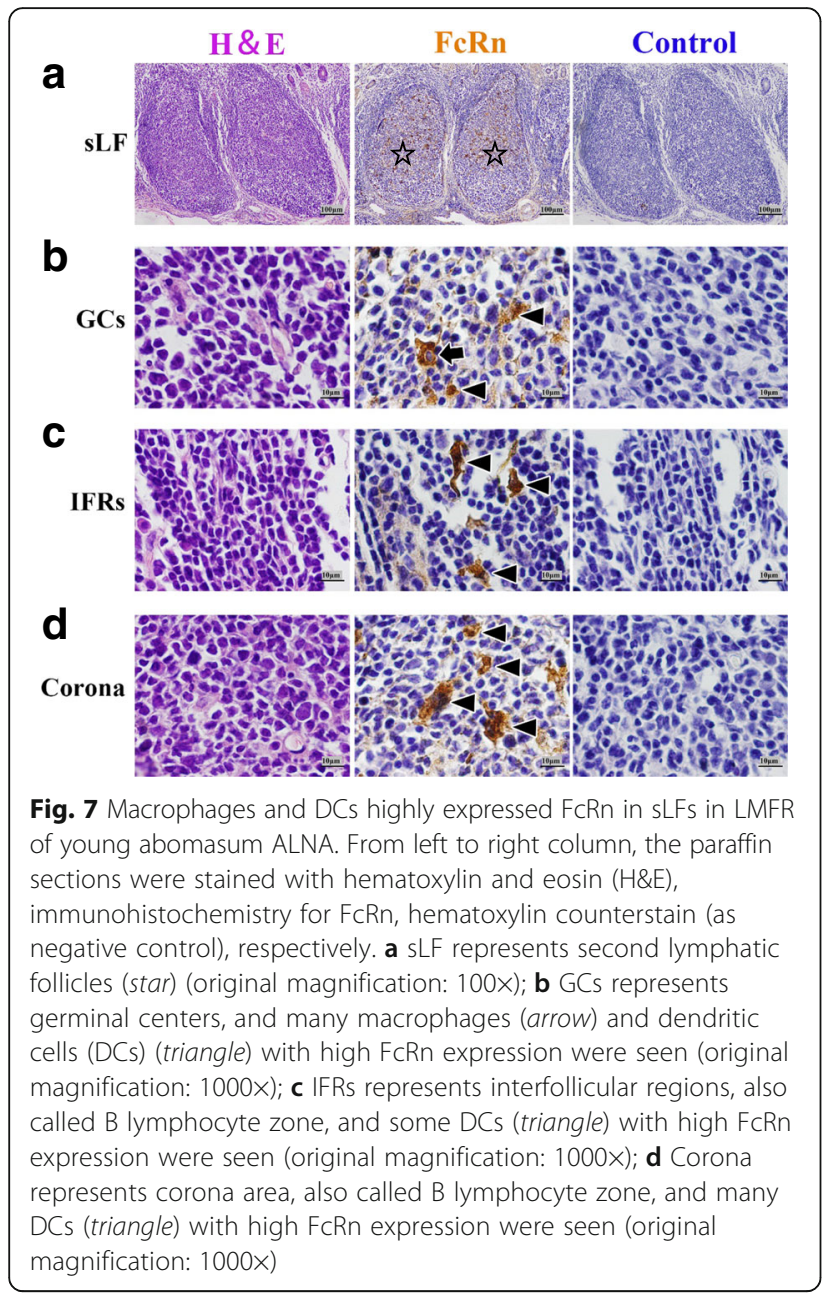

expressed in newborns enterocyte and rapidly declined after weaning in mouse. Researches have demonstrated that FcRn was pH-dependent binding to IgG, with relatively strong binding at acidic $\mathrm{pH}(\mathrm{pH} \leq 6.5)$ and negligible binding at physiological $\mathrm{pH}$ (7.3-7.4) [43]. Some studies reported that the $\mathrm{pH}$ was 5.55 in the camel abomasum [45], which was just within the range of optimal $\mathrm{pH}$ value for FcRn binding to IgG. Thus, FcRn expression in the mucosal epithelial cells of ALNA in abomasum of Bactrian camels of different ages could provide a powerful evidence for FcRn participating in the transmembrane transport of $\operatorname{IgG}$ and associated antigens (especially the transportation of $\mathrm{HCAb})$.

Compared with non-FAE, the FAE is a kind of specialized epithelium, on which the unique microfolds cell (M cell) could efficiently uptake and transport macromolecules and microorganisms in gut lumen to the underlying lymphoid tissue [46]. The MOD measuring results of FcRn expression in epithelial cell of this area found

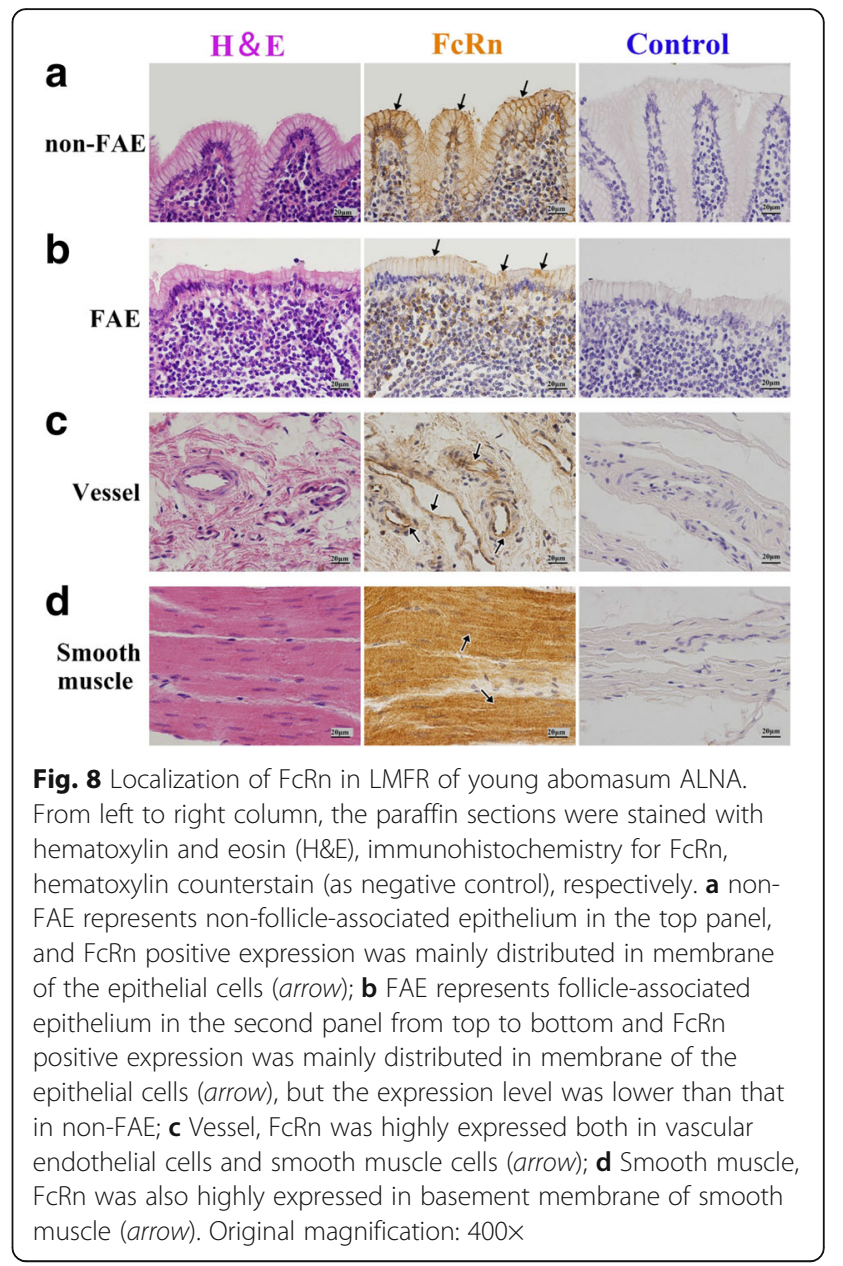

that the FcRn expression level in FAE and non-FAE had no difference in the fetus and young groups, respectively $(P>0.05)$, while that in FAE was significantly lower than that in non-FAE in pubertal and middle-aged groups, respectively $(P<0.05)$. The expression characteristics were similar to those of pIgR, transport receptor of SIgA, in this area [46]. In ALNA of the fetus to middle-aged Bactrian camels, although the FcRn was expressed in mucosal immune inductive sites FAE, in ALNA of the fetus to old Bactrian camels, mainly in effector sites non-FAE. As for whether FcRn participated in M cells uptaking and transporting associated antigens in FAE of ALNA in abomasum of Bactrian camels remains a further study.

In addition, our results showed that FcRn was expressed in the vessel endothelium and smooth muscle in this area, which was similar to the FcRn expression characteristics in the vessel and smooth of mice and humans [47]. It suggested that the FcRn expression in these sites was mainly related to regulating the half-life of IgG and albumin and homeostasis in this local region. 


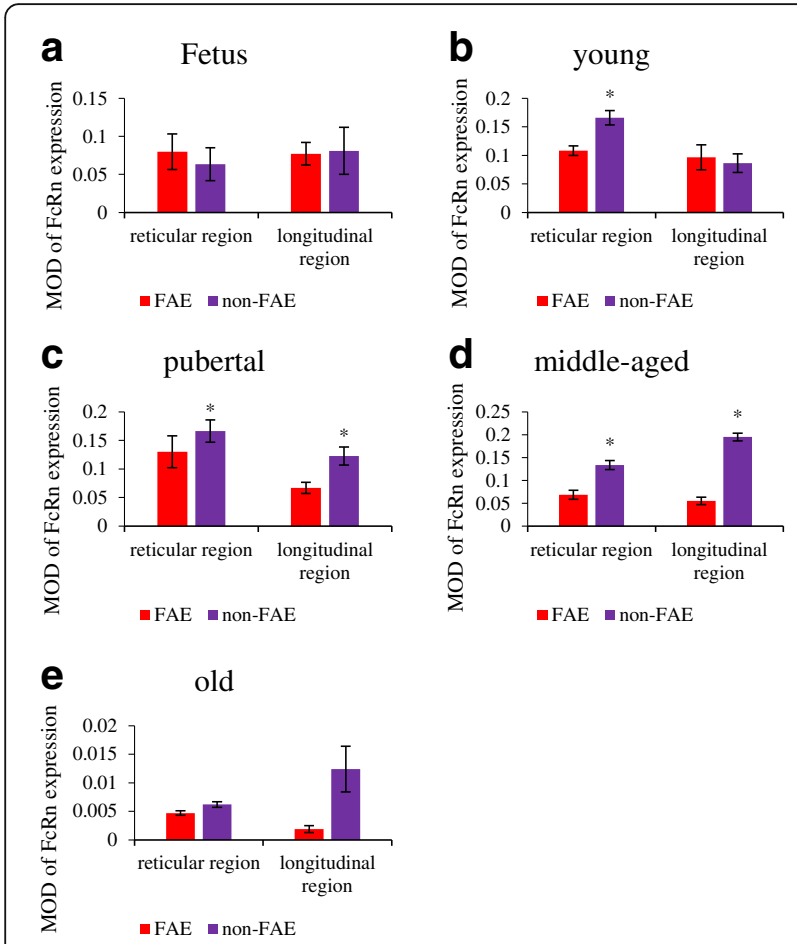

Fig. 9 FCRn expression level in abomasum ALNA of Bactrian camels of different ages. Diagram a to e represent the FcRn expression levels in mucosa epithelium from fetus to old group, respectively. In RMFR, the expression levels of FCRn in non-FAE were significantly higher than those in FAE in young, pubertal and middle-aged groups, respectively $(P<0.05)$, but there were no significant differences in fetus and old groups $(P>0.05)$. In LMFR, the expression levels of $F C R n$ in non-FAE were significantly higher than those in FAE in pubertal and middle-aged groups $(P<0.05)$, but there were no significant differences in fetus, young and old groups $(P>0.05)$. ${ }^{*} P<0.05$, significant differences compared with FAE

In the present study, both macrophages and DCs in sLFs of ALNA in abomasum of Bactrian camels highly expressed FcRn, respectively. Researches have shown that there was mononuclear phagocyte system composed of monocytes, DCs and macrophages in sLFs. And in this system, different types of cells had different subtypes, respectively, and were distributed in special regions [48-53]. They played an important role in antigen capture, processing and presentation, secreting cytokines and regulating immune tolerance $[54,55]$. These results provided an evidence that FcRn could participate in regulating the immune response and tolerance in the sLFs of ALNA in abomasum of Bactrian camels.

\section{Conclusions}

Our results showed that FcRn was mainly expressed in non-FAE, the effector sites, although which was expressed in FAE, the inductive sites for mucosal immunity. And it was also expressed in DCs and macrophages in SLFs of all

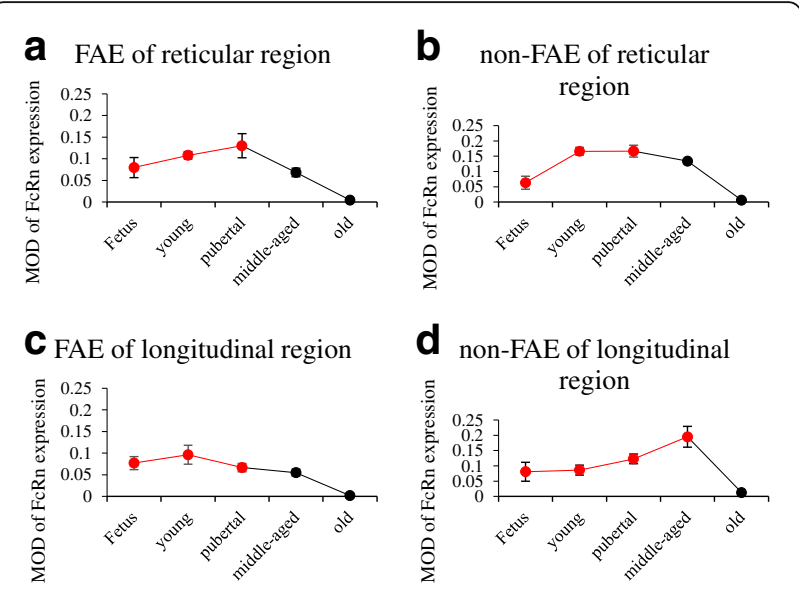

Fig. 10 Changes in FcRn expression in mucosal epithelium of abomasum ALNA with age. Diagram a to $\mathbf{d}$ represent the changes in FCRn expression with age in FAE of RMFR, non-FAE of RMFR, FAE of $L M F R$, non-FAE of $L M F R$, respectively. Red lines represent increase with age, and black lines represent decrease with age. The results showed that in the FAE and non-FAE of RMFR, the FCRn expression level peaked at the pubertal period, and then significant decreased with age. The case was similar in the FAE of LMFR, however, the FCRn expression level in non-FAE of LMFR peaked at Middle-aged period, and then significant decreased with age. It probably related to the upregulation of compensatory reflection because of the FcRn expression level was decreased in other site in this period. In Old group, the FcRn expression level was very low, and it probably related to the degradation of the mucosal immune

or immunosenescence

ages of Bactrian camels. This provided a powerful evidence that IgG could participate in mucosal immune and immune response and tolerance in this area.

\section{Abbreviations}

FcRn: Neonatal Fc receptor; ALNA: Aggregated lymphoid nodules area; RMFR: Reticular mucosal folds region; LMFR: Longitudinal mucosal folds region; MALT: Mucosa-associated lymphoid tissue; MECs: Mucosal epithelial cells; non-FAE: Non-follicle-associated epithelium; DCs: Dendritic cells; pLFs: Primary lymphoid follicles; SLFs: Secondary lymphoid follicles; HCAb: Heavy chain antibody; IHC: Immunohistochemistry; MOD: Mean optical density; SED: Subepithelial dome; IFRs: Interfollicular regions; M cell: Microfolds cell

\section{Acknowledgements}

We would like to thank Dr. Wanling Yao. (Institute of Traditional Chinese Veterinary Medicine, College of Veterinary Medicine, Gansu Agricultural University) for her assistance with English.

\section{Funding}

This study was supported by Grant sponsor: National Natural Science Foundation of China; Grant number: 31260595. Grant sponsor: National Natural Science Foundation of China; Grant number: 30671549 . The Fostering Foundation for the Excellent Ph. D. Dissertation of Gansu Agricultural University; Grant number: 2013001.

\section{Availability of data and materials}

The data set supporting the results of this article are available from the corresponding author. 


\section{Authors' contributions}

Conceived and designed the experiments: WHW, WDZ. Performed the experiments: WDZ. Analyzed the data: WDZ. Contributed reagents/materials/ analysis tools: WDZ, SXL, SJ, XFZ and TTC. Contributed to the writing of the manuscript: WDZ. All authors read and approved the final manuscript.

\section{Competing interests}

The authors declare no financial or commercial conflict of interest.

\section{Consent for publication}

Not applicable.

\section{Ethics approval and consent to participate}

In this study, all experimental procedures were approved by the Animal Care and Use Committee (IACUC) of College of Veterinary Medicine of Gansu Agricultural University. (Approval No: GSAU-AEW-2013-0010) All efforts were made to minimize suffering.

\section{Received: 20 January 2016 Accepted: 31 August 2016}

\section{Published online: 20 October 2016}

\section{References}

1. Fagarasan S, Honjo T. Intestinal IgA synthesis: regulation of front-line body defences. Nat Rev Immunol. 2003;3(1):63-72.

2. Mostov KE. Transepithelial transport of immunoglobulins. Annu Rev Immunol. 1994;12(1):63-84.

3. Macpherson AJ, McCoy KD, Johansen FE, Brandtzaeg P. The immune geography of IgA induction and function. Mucosal Immunol. 2008;1(1):11-22.

4. Norderhaug I, Johansen F, Schjerven H, Brandtzaeg P. Regulation of the formation and external transport of secretory immunoglobulins. Crit Rev Immunol. 1999;19(5-6):481-508.

5. Kaetzel CS, Bruno ME. Epithelial transport of IgA by the polymeric immunoglobulin receptor. US: Springer; 2007:43-89.

6. Dickinson BL, Badizadegan K, Wu Z, Ahouse JC, Zhu X, Simister NE, et al. Bidirectional FCRn-dependent lgG transport in a polarized human intestinal epithelial cell line. J Clin Invest. 1999;104(7):903-11.

7. Yoshida M, Claypool SM, Wagner JS, Mizoguchi E, Mizoguchi A, Roopenian DC, et al. Human neonatal Fc receptor mediates transport of IgG into luminal secretions for delivery of antigens to mucosal dendritic cells. Immunity. 2004;20(6):769-83.

8. Yoshida M, Kobayashi K, Kuo TT, Bry L, Glickman JN, Claypool SM, et al. Neonatal Fc receptor for lgG regulates mucosal immune responses to luminal bacteria. J Clin Invest. 2006;1 16(8):2142-51.

9. Jones EA, Waldmann TA. The mechanism of intestinal uptake and transcellular transport of IgG in the neonatal rat. J Clin Invest. 1972;51(11):2916-27.

10. Rodewald R. pH-dependent binding of immunoglobulins to intestinal cells of the neonatal rat. J Cell Biol. 1976;71(2):666-9.

11. Rodewald R, Kraehenbuhl JP. Receptor-mediated transport of IgG. J Cell Biol. 1984;99(1 Pt 2):159s-64s.

12. Borthistle BK, Kubo RT, Brown WR, Grey HM. Studies on receptors for IgG on epithelial cells of the rat intestine. J Immunol. 1977;119(2):471-6.

13. Simister NE, Mostov KE. An FC receptor structurally related to MHC class I antigens. Nature. 1989;337(6203):184-7.

14. Burmeister WP, Gastinel LN, Simister NE, Blum ML, Bjorkman PJ. Crystal structure at 2.2 A resolution of the $\mathrm{MHC}$-related neonatal Fc receptor. Nature. 1994;372(6504):336-43.

15. Israel E, Taylor S, Wu Z, Mizoguchi E, Blumberg R, Bhan A, et al. Expression of the neonatal Fc receptor, FCRn, on human intestinal epithelial cells. Immunology. 1997;92(1):69-74.

16. Haymann JP, Levraud JP, Bouet S, Kappes V, Hagege J, Nguyen G, et al. Characterization and localization of the neonatal Fc receptor in adult human kidney. J Am Soc Nephrol. 2000;11(4):632-9.

17. Kobayashi N, Suzuki Y, Tsuge T, Okumura K, Ra C, Tomino Y. FcRn-mediated transcytosis of immunoglobulin $\mathrm{G}$ in human renal proximal tubular epithelial cells. Am J Physiol Renal Physiol. 2002;282(2):F358-65.

18. Spiekermann GM, Finn PW, Ward ES, Dumont J, Dickinson BL, Blumberg RS, et al. Receptor-mediated Immunoglobulin G Transport Across Mucosal Barriers in Adult Life: Functional Expression of FcRn in the Mammalian Lung. J Exp Med. 2002;196(3):303-10.
19. Cianga P, Cianga C, Cozma L, Ward ES, Carasevici E. MHC class I related FC receptor, FCRn, is expressed in the epithelial cells of the human mammary gland. Human Immunology. 2003;64(12):1152-59.

20. Korthagen NM, van Bilsen K, Dik WA, Bastiaans J, Kolijn M, Kuijpers RW, et al. FcRn mediated lgG transport by retinal pigment epithelium cells. J Transl Med. 2012;10 Suppl 3:2.

21. Li Z, Palaniyandi S, Zeng R, Tuo W, Roopenian DC, Zhu X. Transfer of IgG in the female genital tract by $\mathrm{MHC}$ class I-related neonatal Fc receptor (FcRn) confers protective immunity to vaginal infection. Proc Natl Acad Sci. 2011; 108(11):4388-93.

22. Ober RJ, Martinez C, Vaccaro C, Zhou J, Ward ES. Visualizing the Site and Dynamics of IgG Salvage by the MHC Class I-Related Receptor, FCRn. J Immunol. 2004;172(4):2021-9.

23. Antohe F, Rădulescu L, Gafencu A, Gheție V, Simionescu M. Expression of functionally active FCRn and the differentiated bidirectional transport of lgG in human placental endothelial cells. Hum Immunol. 2001;62(2):93-105.

24. Baker K, Qiao SW, Kuo TT, Aveson VG, Platzer B, Andersen JT, et al. Neonatal Fc receptor for $\lg G$ ( $F C R n$ ) regulates cross-presentation of $\lg G$ immune complexes by CD8-CD11b + dendritic cells. Proc Natl Acad Sci U S A. 2011; 108(24):9927-32.

25. Zhu X, Meng G, Dickinson BL, Li X, Mizoguchi E, Miao L, et al. MHC Class IRelated Neonatal Fc Receptor for lgG Is Functionally Expressed in Monocytes, Intestinal Macrophages, and Dendritic Cells. J Immunol. 2001;166(5):3266-76.

26. Shah U, Dickinson BL, Blumberg RS, Simister NE, Lencer WI, Walker WA. Distribution of the IgG Fc receptor, FcRn, in the human fetal intestine. Pediatr Res. 2003;53(2):295-301.

27. Yoshida M, Masuda A, Kuo T, Kobayashi K, Claypool SM, Takagawa T, et al. IgG transport across mucosal barriers by neonatal Fc receptor for IgG and mucosal immunity. Springer Semin Immunopathol. 2006;28(4):397-403.

28. Ghetie V, Hubbard JG, Kim JK, Tsen MF, Lee Y, Ward ES. Abnormally short serum half-lives of IgG in $\beta 2$-microglobulin-deficient mice. Eur J Immunol. 1996;26(3):690-6.

29. Catunda Lemos AP, Cervenak J, Bender B, Hoffmann OI, Baranyi M, Kerekes $A$, et al. Characterization of the rabbit neonatal Fc receptor (FcRn) and analyzing the immunophenotype of the transgenic rabbits that overexpresses FCRn. PLoS One. 2012;7(1):e28869.

30. Ye L, Tuo W, Liu X, Simister NE, Zhu X. Identification and characterization of an alternatively spliced variant of the MHC class I-related porcine neonatal Fc receptor for IgG. Dev Comp Immunol. 2008;32(8):966-79.

31. Mayer B, Zolnai A, Frenyó LV, Jancsik V, Szentirmay Z, Hammarström L, et al. Redistribution of the sheep neonatal Fc receptor in the mammary gland around the time of parturition in ewes and its localization in the small intestine of neonatal lambs. Immunology. 2002;107(3):288-96.

32. Kacskovics I, Wu Z, Simister NE, Frenyó LV, Hammarström L. Cloning and characterization of the bovine MHC class I-like Fc receptor. J Immunol. 2000;164(4):1889-97.

33. Sayed-Ahmed A, Kassab M, Abd-Elmaksoud A, Elnasharty M, El-Kirdasy A. Expression and immunohistochemical localization of the neonatal FC receptor $(F C R n)$ in the mammary glands of the Egyptian water buffalo. Acta Histochem. 2010;112(4):383-91.

34. Kacskovics I, Mayer B, Kis Z, Frenyo LV, Zhao Y, Muyldermans S, et al. Cloning and characterization of the dromedary (Camelus dromedarius) neonatal Fc receptor (drFcRn). Dev Comp Immunol. 2006;30(12):1203-15.

35. Hamers-Casterman C, Atarhouch T, Muyldermans S, Robinson G, Hamers C, Songa $E B$, et al. Naturally occurring antibodies devoid of light chains. Nature. 1993;363(6428):446-8.

36. Deschacht N, De Groeve K, Vincke C, Raes G, De Baetselier P, Muyldermans S. A novel promiscuous class of camelid single-domain antibody contributes to the antigen-binding repertoire. J Immunol. 2010;184(10):5696-704.

37. Liebler-Tenorio EM, Pabst R. MALT structure and function in farm animals. Vet Res. 2006;37(3):257-80.

38. Wang W-H. Observations on aggregated lymphoid nodules in the cardiac glandular areas of the Bactrian camel (Camelus bactrianus). Vet J. 2003; 166(2):205-9.

39. Xu XH, Wang WH, Gao Q, Qi SS, He WH, Tai LF, et al. The anatomical characteristics of the aggregated lymphoid nodule area in the stomach of Bactrian camels (Camelus bactrianus) of different ages. Vet J. 2010;184(3):362-5.

40. Zhang WD, Wang WH, Xu XH, Zhaxi YP, Zhang LJ, Qi SS, et al. The histological characteristics of the aggregated lymphoid nodules area in abomasum of Bactrian camels (Camelus bactrianus) of different ages. Vet Immunol Immunopathol. 2012;147(3-4):147-53. 
41. Liu S: Practical bio-histological techniques. Beijing: Beijing Science Press; 2006.

42. Wang-dong Z: Study on the purification, preparation of polyclonal antibody of $\mathrm{lg}$ Gs of the Bactrian Camels and the characteristics of distribution of the secrete Ig Gs plasma cells in small intestine. Master's Degree. Lanzhou: Gansu Agricultural University; 2012.

43. Martin WL, West Jr AP, Gan L, Bjorkman PJ. Crystal structure at $2.8 \mathrm{~A}$ of an $\mathrm{FcRn} /$ heterodimeric Fc complex: mechanism of $\mathrm{pH}$-dependent binding Mol Cell. 2001;7(4):867-77.

44. Brandtzaeg P, Kiyono H, Pabst R, Russell MW. Terminology: nomenclature of mucosa-associated lymphoid tissue. Mucosal Immunol. 2008;1 (1):31-7.

45. Maloiy GM, Clemens ET. Gastrointestinal osmolality electrolyte and organic acid composition in five species of East African herbivorous mammals. J Anim Sci. 1980;51(4):917-24

46. Kraehenbuhl J-P, Neutra MR. Epithelial M cells: differentiation and function. Annu Rev Cell Dev Biol. 2000;16(1):301-32

47. Borvak J, Richardson J, Medesan C, Antohe F, Radu C, Simionescu M, et al. Functional expression of the MHC class I-related receptor, FcRn, in endothelial cells of mice. Int Immunol. 1998;10(9):1289-98.

48. Bonnardel J, Da Silva C, Henri S, Tamoutounour S, Chasson L, MontananaSanchis F, et al. Innate and adaptive immune functions of peyer's patch monocyte-derived cells. Cell Rep. 2015;11(5):770-84.

49. Contractor N, Louten J, Kim L, Biron CA, Kelsall BL. Cutting Edge: Peyer's Patch Plasmacytoid Dendritic Cells (pDCs) Produce Low Levels of Type I Interferons: Possible Role for IL-10, TGF, and Prostaglandin E2 in Conditioning a Unique Mucosal pDC Phenotype. J Immunol. 2007;179(5):2690-4.

50. Grouard G, Durand I, Filgueira L, Banchereau J, Liu Y-J. Dendritic cells capable of stimulating T cells in germinal centres. Nature. 1996;384(6607):364-7.

51. Iwasaki A, Kelsall BL. Unique Functions of CD11b+, CD8 +, and DoubleNegative Peyer's Patch Dendritic Cells. J Immunol. 2001;166(8):4884-90.

52. Lelouard H, Henri S, De Bovis B, Mugnier B, Chollat-Namy A, Malissen B, Meresse S, Gorvel JP: Pathogenic bacteria and dead cells are internalized by a unique subset of Peyer's patch dendritic cells that express lysozyme. Gastroenterology 2010, 138(1):173-184 e171-173.

53. Lindquist RL, Shakhar G, Dudziak D, Wardemann H, Eisenreich T, Dustin ML, et al. Visualizing dendritic cell networks in vivo. Nat Immunol. 2004;5(12):1243-50.

54. Lelouard H, Fallet M, de Bovis B, Meresse S, Gorvel JP. Peyer's patch dendritic cells sample antigens by extending dendrites through $\mathrm{M}$ cellspecific transcellular pores. Gastroenterology. 2012;142(3):592-601. e593.

55. Baker K, Rath T, Flak MB, Arthur JC, Chen Z, Glickman JN, et al. Neonatal Fc receptor expression in dendritic cells mediates protective immunity against colorectal cancer. Immunity. 2013;39(6):1095-107.

\section{Submit your next manuscript to BioMed Central and we will help you at every step:}

- We accept pre-submission inquiries

- Our selector tool helps you to find the most relevant journal

- We provide round the clock customer support

- Convenient online submission

- Thorough peer review

- Inclusion in PubMed and all major indexing services

- Maximum visibility for your research

Submit your manuscript at www.biomedcentral.com/submit

) Biomed Central 